\title{
Analysis on the Element Integration of Pop Music and Folk Music
}

\author{
1,a Nie Jun \\ ${ }^{1}$ Qiannan Normal College for Nationalities,Dujun,Guizhou,China,558000 \\ a36908914@qq.com
}

Keywords: Pop music, folk music, element, integration.

\begin{abstract}
The shock brought by pop music to folk music is only on the technical and formal level; the aesthetic quality of pop music is still a presentation of traditional Chinese culture and music and pop music's survival and development is the extension and expansion of folk music; and with pop music becoming mature, it has more and more elements related to folk music. This paper, taking Chinese-style songs as example, analyzes the relationship between folk music and pop music, so as to provide beneficial reference for people on music research and creation.
\end{abstract}

\section{Introduction}

In recent years, with the development of Chinese pop music, the exchanges between oriental and western music culture become more and more frequent; at the same time of plenty of western pop music swarming into China, more and more excellent Chinese music works meet the world and have received focus and good comment from western music world. With the development and improvement of our national economy, people's needs on music show features of variety and multilevel, driving musical culture to develop towards the direction of diversification. The integration of pop and folk elements is a strong tend of music development now; creative songs connecting pop music with folk music increase constantly in China, promoting Chinese-style songs to develop in present song circle. For example, among the songs by Phoenix Legend, Leehom Wang and other singers, on one hand, most of them show pop and fashionable elements suitable for the trend; one the other hand, they mostly have unique Chinese national elements, providing audience with new auditory sense, deeply loved by audience. Based on this, this paper combines the folk music with pop music, creating a kind of music filled with national features as well as pop elements and making the audience feel pleased.

\section{Elements in Folk Music Works}

There are plenty of programs in Chinese national vocal music art, about 40 thousand in record. These programs have their own unique art features and charm, some of which are classic and have gone through long time's test, winning a number of fans. Therefore, it is necessary and important for pop music to get inspiration of creation and singing from national vocal music works, such as "New Kangting Love Song” by Zang Tianshuo, “Sing Liuyang River” by Song Zuying, and other works are created on the basis of national vocal music works. In the efforts of pop music seeking for inspiration from national vocal music works, it is frequently seen that national vocal music works are sang in pop way, such as "Memories of Comrades" and "Kangting Love Song” by DaoLang, "Flying Goose" and "Pastoral” by Black Duck, and “On Beijing's Golden Mountain” by Han Hong, and so on. Besides, some concert performers or bands play panpipe, koto, urheen, dulcimer and other folk musical instruments.

Broadly speaking, all of the pop music in China are national, reflecting Chinese living state, spiritual temperament, values, aesthetic orientations and so on; as human beings have similar or same directions in expressing emotions and pursuing spirits, the national characters of some text contents are not obvious, such as the numerous love songs; their theme is the common thing of all the human beings, and it is difficult to judge their national affiliation. The national elements of pop music are those typical and profound elements with Chinese cultural patterns. 
The folk music elements in pop music are both the rebellion and overturn of traditional music, and regurgitation-feeding and reconstruction of traditional music. This fact not only proves resource value and culture value that folk music owns, equipping it with new aesthetic quality and art charm, but also opens a broader channel for folk music's transmission, making people, especially pop music lovers feel and experience the charm of folk music. From another point of view, no matter how much western hue that pop music has, Chinese pop music basically is the outcome of Chinese culture and Chinese music, the music expression of Chinese national emotions and spirits, the representation of Chinese musical thoughts, music creation and music aesthetics, and the objective appearance of diversified development of folk music. Therefore, pop music, fundamentally, an organic component of Chinese music, belongs to Chinese cultural system; it is a kind of expansion and extension of Chinese folk music, a kind of deformation and innovation, a school and a branch. Thus, it is more accurate to say that Chinese music takes examples by western pop music types and gains new way of expression, than to say that it loses some traditional elements after shocked by western pop music. It is more accurate to say that traditional music exists in another way than to say it is repressed by pop music. pop music and folk music are learn from each other and integrate into each other, both of which realize their own art value and charm, creating new music and culture in the cultural soil in China together.

\section{Integration of Folk Music and Pop Music}

It is still controversial on the integrated development of folk music and pop music. Some people think that pop music is non-mainstream music, and only folk music is mainstream; there is no integration of they two and pop music will hinder folk music's development and lowers its quality. However, in the development process of music, we can see that folk music is the pop music in old times and pop music will become folk music in the future; they two are in a state of mutual conflict and mutual attraction; that is to say, there are common part of national and pop music, and only when they develop together, can Chinese music gain long-term sustainable harmonious development. For example, the famous singer, Deng Lijun sang folk songs in the form of pop music. The Chinese-style in pop music can not only show musicians' pursuit for fashion, but also show that they attach importance to traditional folk music.

Although folk music's development suffered shocks from jazz, rock and roll, POP and other pop music, it seeks for development in the trend of pop music with its inclusive advantage, which means folk music puts its typical music elements into pop music and drives pop music to develop. In the present stage, the trend of Chinese-style songs makes our folk music rise and welcome by the public. This kind of combination makes folk music richer in content and more suitable for modern people's aesthetic needs, which promotes more young people understand Chinese traditional music; at the same time, it increases people's sense of identity and affiliation to Chinese traditional music. For example, the typical Chinese-style song "May we all be blessed with longevity" is still sung by many people, and its lyric is take the lines in "Prelude To Water Melody" by Su Shi, a writer in Song Dynasty in China; the deep Chinese national elements make the combination of traditional and pop music possible and this connection suits modern people's psychological needs and meets people's needs for spiritual cultural products in a deeper level.

Folk music is the basis of pop music and pop music has greater vitality in the soil of folk music. Chinese-style songs is the outcome of integration of pop music and folk music. Different branches of pop music absorb unique Chinese national cultural elements, driving the mutual development of pop and folk music. The social development promotes changes in people's thoughts, and people start to treat music with diverse thoughts and attitudes; traditional music, to some extent, inhibits music's development. However, the application of folk music elements in pop music, outstands the features of pop music, and highlights Chinese pop music's features. In the aspect of the integration of pop music and folk music, we should stick to the open and inclusive cultural attitude, to meet the audial needs of different people in the world. Chinese-style songs are pop, which is a direct evidence for that; adding folk music's elements in pop music and effectively promotes folk music's development,and this 
combination makes Chinese pop music more and more powerful in endurance and inclusiveness under the shocks of all kinds of music trends.

\section{Empirical Analysis of the Element Integration of Pop Music and Folk Music}

Local Musicians of Han Nationality Add Elements of Minority Music into pop Music: Since late 1990s, musicians of Han nationality start to nationalize pop music. They make covers of folk songs, create songs with folk songs' features, and add folk musical instruments in pop music orchestration. Take DaoLang's music as an example: Daolang makes covers of 10 Sinkiang folk songs, such as, "Memories of Comrades”, "Night on the Grassland”, "A Wa Guli” and so on. He adds rock band orchestrate and tambourine, tambur, Ejieke and other national instrument into his original songs, such as his master piece "First Snow in 2002". In Picture 1, it is a part of the song "First Snow in 2002", in the beginning, middle and end, tambur is used in the orchestration; the melody and rhythm have Uyghur music style, such as la mode similar to Uyghur style, and the rhythm adopts much tautophony.

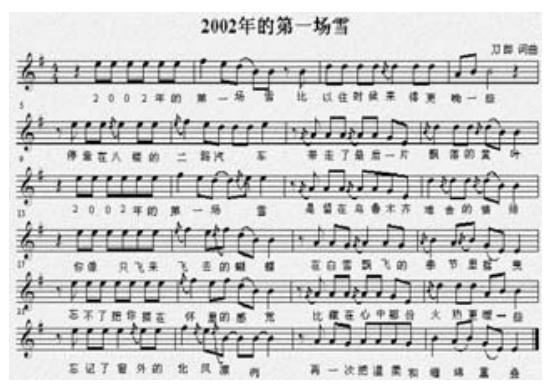

Picture 1. First Snow in 2002

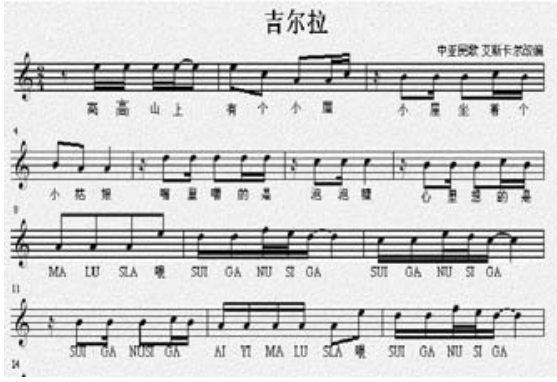

Picture 2. Marusha

Pop Music Elements Added into Songs by Folk Musicians: Folk musicians start to adopt orchestrate mode of pop music. In the early 1980s, guitar was used to play music, and in the 1990s, pop music instruments and national instruments are integrated, such as Esqer Memet's Graywolf band, Afanty band, and Arken band. After the 21st century, fashion elements are integrated, for example, Arken integrates R\&B, Rap, Hip-Hop elements into Kazakhstan folk music, and creates new songs: Miss U, Oh Mimmy! Feat Shawty-Yi, Is She still crying, and so on. Now, electronic drums, electric guitars, electronic organs and synthesizers and other orchestrates can be heard in Uyghur pop songs. Picture 2 is a part of Marusha, which was a folk song and the melody and rhythm show some Uyghur music elements; later, as it is sung by many Uyghur singers, it becomes more and more pop within the nationality; there are wooden guitar, drum set, bass, electric guitar and other international pop music elements.

The melody and rhythm are revised and the lyrics are recomposed; folk music elements are borrowed to create many music works, which impose an effect of inheriting and advocating folk music. All of the practice has promoted folk music to integrate with outer music culture. Since the 1980s, this kind of practice has never stopped, which is closely connected to the localization of pop music in Sinkiang; the cultural integration is the same as the development of localization process of contemporary pop music, which is an inevitable element in the localization process of contemporary pop music.

Take the recomposition of Luobin Wang's folk songs as an example:

(1) The song "Lifting Your Veil” came from a folk song "Aria” in the 1950s, the melody of which is:

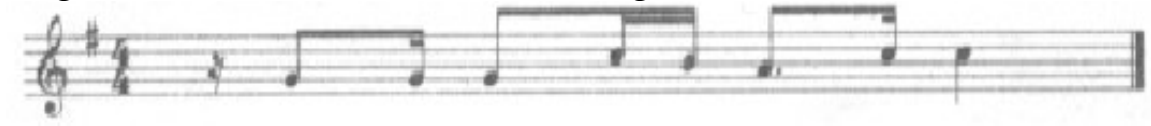

Picture 3: melody of the first line

To suit the pronunciation of "Lift" ("Xian” in Chinese), Luobin Wang changed it into:

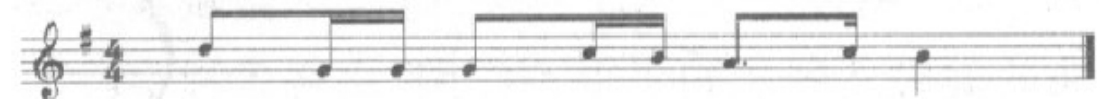

Picture 4: change in melody 
Then, to suit the aesthetic needs of Han nationality, the lyrics are "Your mouth is red and small, like sweet cherry in May".

Joint Analysis of Element in Chinese Folk Art Forms and pop Music: There are as many as four hundred types of drama and more than three hundred operas, and every type has its unique art charm. Therefore, to integrate the charm into music creation is one of the means of music innovation. "Love of Butterfly", and "Ode to the Plum Blossom" respectively use the melody of story-telling and ballad singing in Suzhou dialect and the music style of Sichuan opera. "Huansha Girls", and "Shanxi opera shouting” respectively integrate into Huangmei opera and Shanxi opera's art style. pop music, as the most empirical pop music, also uses opera means to seek for difference. The typical one is "Love Complaint" by Liu Huan, which has the features of Beijing opera, and especially the prolongation of tune at the end makes the charm deeper; the audience cannot even distinguish whether it is Beijing opera or pop songs. "Stall tea" and "Bridge in Beijing" blend the art style of story-telling in Beijing dialect with drum, with full-bodied fashion hue and special Beijing flavor. Certainly, the reference of pop music on the skills and styles of drama is not much. However, it fully and completely proves the active aspect of folk music elements in pop music. For example, the song "Love, love, love" in recently pop program of "The voice of China" is sung by Wang Hongdi incisively and vividly, which expresses the charm of Beijing charm, giving every audience spiritual shock and resonance.

\section{Conclusion}

As a kind of music form of entertainment, fashion and business, pop music lacks in content and lyrics in its early period, and cannot have classic works; most of the pop songs are forgot after a period. Therefore, to promote the development of folk music and pop music, on one hand, musicians need to add fashion element in folk music, and innovate the expressing ways of folk music; on the other hand, pop music should absorb cultural elements in folk music, so as to elevate the cultural connotation of pop music and to create more music works with high cultural value and art value, to make the integration of folk music and pop music perfect and to enhance the level of music creation in China in the process of fully making use of the common and different points of the two parts.

\section{References}

[1] Zhou Min; “On the "Feng Ya Song” of pop Music” [J] ; Voice of Yellow River; 2012(14): 117-118.

[2] Ma Jun. “Cultural Studies of 'Chinese-style’ pop music” [D]. Central China Normal University, 2008.

[3] .Li Shen. Nakhi Musical Culture in Urbanization Process [J]. Journal of Yunnan Academy of Art, 2001 (4) : 18-22

[4] Fan Xia. Brief Analysis of National Style of pop Music [J]. Journal of Writers, 2009 (6) : 19-22.

[5] Zhu Wenjun. On the Integration of Folk Music and pop Music [J]. Intelligence, 2009 (1) : 112-113.

[6] Li Shuqiong. Analysis on the Art Features and Influence of Daolang's Music Works [J]. Music Creation, 2009(2):243-45.

[7] Zhang Jian. Flute, Bamboo Flute and Electronic Music [D]. Beijing: Chinese Conservatory of Music, 2011.

[8] Liu Xingeng, Hao Wei. Singing Course of pop Music [M].Shanghai Conservatory Of Music, 2011.

[9] Ceth. Sa Dingding-Full Phat Remix- Oriental Singer[J].Pu'er, 2011,(1):33-37. 